\title{
SOBRE A CONJUGAÇÃO VERBAL EM SALA DE AULA
}

\author{
Renira Lisboa de Moura Lima \\ Programa de Pós-Graduação em Letras \\ Universidade Federal de Alagoas
}

O sistema verbal da Língua Portuguesa é muito complexo. Não se estranha, pois, que seja considerado, mesmo no aspecto morfológico, um verdadeiro terror pelos estudantes que chegam ao ensino superior - mesmo ao curso de Letras - sem o domínio de habilidades simples, como identificar e conjugar os tempos verbais.

Depoimentos de alguns deles e uma longa experiência de ensino e de orientação nas disciplinas Lingua Portuguesa e Prática de Ensino permitem dizer que o processo de ensino/aprendizagem da conjugação verbal se apóia na memória auditiva, mantendo-se fixa a seqüência das flexões apresentada nos manuais de gramática e nos livros didáticos ditada pelos pronomes eu - tu - ele - nós - vós - eles. Mas a memória trai com muita freqüência, por insuficiência de treino ou de uso; o "vírus" do esquecimento, então, ataca alguns de seus "arquivos". Além disso, a falta de convívio com algumas das formas paradigmáticas, na língua oral quotidiana - de que são exemplos as que correspondem aos pronomes tu e vós, em todos os tempos verbais; a forma simples do pretérito maisque-perfeito e o futuro do pretérito do indicativo -, deixa o aluno inseguro, pois essas formas the soam "estranhas". Esse método mnemônico auditivo, portanto, não se prova útil, contrariando a meta de qualquer ensino: dar segurança e autonomia.

Diante desse quadro, apresentam-se, sem a inconveniente memorização pura e simples, sugestões para o ensino da conjugação: algumas são teóricas, com base em princípios pedagógicos; outras, práticas, com aplicação de conhecimentos lingüísticos e de recursos de sistematização. 
Não se trata, no entanto, de uma proposta de erradicação do uso da memória no processo de ensino/aprendizagem - o que não é possível, nem desejável - e sim, de uma redução do esforço de memorização. Isso pode ser feito, no caso da conjugação verbal, através de uma reconstrução a partir de elementos básicos. É o que se pretende comprovar com este artigo.

\section{SUGESTÕES TEÓRICAS}

A escolha de qualquer conteúdo de ensino - busca de uma resposta para a pergunta Que ensinar?- não é aleatória, mas intencional, aplicando-se critérios de seleção. Para responder-se a pergunta Que verbos ensinar a conjugar?, aplicam-se os seguintes principios pedagógicos, combinados:

1. Princípio da freqüência - selecionam-se os verbos mais freqüentes. Isso pode ser feito até em jornais: numa rápida coleta, constatou-se a alta freqüência de uso dos verbos dever, estar, faltar, fazer, ir, poder, provocar, querer, ser, ter, trazer.

2. Princípio da complexidade - escolhem-se os verbos em que podem ocorrer os "erros previsíveis", como nas formas pouco usadas de verbos irregulares (tendes, pondes, ledes, no presente do indicativo; tragais, vades, no presente do subjuntivo);

3. Princípio da carência - ensina-se o que não se sabe, a partir do que se sabe. Há um ponto de chegada (as formas desconhecidas ou pouco utilizadas) e um ponto de partida (as que já fazem parte da experiência lingüística). Por exemplo, na língua oral quotidiana, as formas verbais correspondentes ao pronomes eu, ele/você são conhecidas e utilizadas por todos os falantes. ${ }^{1}$ Só uma parte deles, porém, já têm incorporadas, graças a sua experiência de vida, as correspondentes às pessoas gramaticais eu, ele(s)/você(s), nós. O ponto de partida e o ponto de chegada vão, assim, diferir de um grupo para

Para alguns, há apenas duas formas no paradigma da conjugação: a de $1^{\text {: }}$ pessoa se opõe a uma forma usada para todas as outras pessoas. É o caso de vou (eu) por oposição a vai (ele/você, nós, vocês/eles). 
outro - o ensino tem que ser diversificado -, mas as formas correspondentes aos pronomes tu e vós, certamente, serão ponto de chegada para todos eles. ${ }^{2}$

4. Principio da continuidade - garante-se a presença dos temas básicos ao longo do curso. Nada é apresentado de uma só vez, num único momento, quando se trata de ensino/aprendizagem. Não se pode, por exemplo, selecionar o tópico "Conjugação verbal" como uma unidade de ensino em apenas uma série do período escolar.

5. Princípio da seqüenciação - ampliam-se e aprofundam-se os conhecimentos em cada "revisita" ao conteúdo. Incluir-se um tópico em diversos momentos do período escolar não significa que vai ser igualmente trabalhado. Na conjugação verbal, por exemplo, ampliam-se, num mesmo tempo verbal, as desinências de número e de pessoa; aumenta-se o número de tempos verbais; incluem-se novos verbos. Dessa forma, dominado num aspecto, o conteúdo passa a ser considerado o ponto de partida para a etapa seguinte, como numa interminável cadeia.

6. Principio da integração - existem zonas de intersecção dos diferentes assuntos de uma disciplina (integração intradisciplinar) ou de disciplinas diferentes (integração interdisciplinar). Na conjugação verbal, dá-se uma integração intradisciplinar com os tópicos acentuação, colocação pronominaß ${ }^{\beta}$ e classificação de orações, ${ }^{4}$ entre outros; e uma

2 Não se pode dizer que os alunos não têm acesso a essas formas verbais. Elas ocorrem em situações especificas, mas freqüentes, como no discurso religioso em que o aluno é falante (utilizando-as - às vezes com deturpação - mecanicamente em orações, preces, jaculatórias); ouvinte (de sermões ou de leituras do sacerdote ou pastor); e leitor (de trechos da Bíblia).

3 No futuro do presente e do pretérito do indicativo, só existe a possibilidade de ocorrência da próclise e da mesóclise (far-nos-á, não nos fará); e, nos tempos verbais das orações subordinadas desenvolvidas, da próclise (Quero que você me explique esta fórmula).

4 Uso do pretérito imperfeito ou do futuro do subjuntivo nas orações subordinadas adverbiais condicionais e do futuro do pretérito e do presente, nas orações principais correspondentes (Se você pudesse, faria essa viagem/ se você puder, fará essa viagem; uso do presente do 
integração interdisciplinar, na produção e na leitura de textos de outras disciplinas. ${ }^{5}$

\section{SUGESTÕES PRÁTICAS}

Com as seguintes sugestões de ordem prática, exemplificadas com alguns verbos irregulares bem freqüentes, pretende-se demonstrar, que se pode evitar o uso da memorização como única capacidade mobilizada no processo de ensino da conjugação.

1. Agrupar os verbos selecionados, adotando-se o critério da semelhança de características que, muitas vezes, não são percebidas, pois os verbos são aprendidos isoladamente. Servem, como exemplo, estes cinco grupos, respeitando-se esta seqüência: (a) dizer, fazer, trazer, (b) dar, estar, ser, (c) pôr, ter, ver, (d) crer, ir, ler, rir, ver, e (e) caber, saber.

2. Utilizar, como tópico, o tempo verbal. Quando um mesmo tempo é estudado para todos os verbos, evita-se a aprendizagem fragmentada (um verbo, como tópico, leva ao estudo paradigmático de todos os seus tempos) e permite-se a integração (uso dos tempos verbais e sua correspondência na produção/leitura de textos).

3. Adotar uma seqüência das pessoas gramaticais adequada aos tempos estudados, com aplicação de dois critérios: o da carência e o da complexidade. Daí decorrem quatro seqüências: (A) para o Indicativo (presente, pretérito imperfeito e mais-que-perfeito, futuro do presente e do pretérito) e para o subjuntivo (presente, pretérito imperfeito e futuro): eu - ele/você $\rightarrow$ eles/vocês- tu $\rightarrow$ nós - vós; (B) para o pretérito perfeito do indicativo: eu - ele/você - eles/vocês $\rightarrow$ nós

subjuntivo nas orações subordinadas substantivas, como em $\dot{E}$ possivel que você venha).

5 Serve de exemplo o emprego dos tempos verbais em correspondência, como o futuro do pretérito do indicativo/pretérito imperfeito do subjuntivo na apresentação de hipóteses; do presente do indicativo, na enunciação de princípios; do jogo pretérito perfeito/pretérito imperfeito do indicativo, nos relatórios; do pretérito imperfeito do indicativo, nas descrições; do futuro do presente, nas previsões. 
- tu - vós; (C) para o imperativo (afirmativo e negativo): você vocês - nós $\rightarrow$ tu - vós; e (D) para o futuro do presente do indicativo: ele/você - eles/vocês - tu $\rightarrow$ eu - nós - vós.

4. Empregar, para a identificação dos modos e tempos, palavras-teste que são admitidas pelo modo - com certeza (indicativo) e talvez (subjuntivo) - e pelos tempos verbais simples: agora (presente); antigamente (pretérito imperfeito); ontem (pretérito perfeito); antes disso já (pretérito mais que perfeito); amanhã (futuro do presente); se fosse possível (futuro do pretérito) e quando amanhã (futuro do subjuntivo).

5. Respeitar uma seqüência na apresentação dos tempos verbais, como, por exemplo, a seguinte:
A) 1. Indicativo presente $\Rightarrow 2$. Subjuntivo presente $\Rightarrow 3$. Imperativo
4. Pretérito imperfeito do indicativo
B) 5. Pretérito perfeito $\Rightarrow 6$. Pretérito mais-que-perfeito do indicativo do indicativo $\Downarrow$
7. Pretérito imperfeito $\Rightarrow 8$. Futuro do subjuntivo do subjuntivo
C) 9. Futuro do presente $\Rightarrow 10$. Futuro do pretérito

6. Dosar a utilização de termos técnicos conforme o desenvolvimento da turma.

Com essas sugestões, organiza-se o ensino da conjugação verbal dos tempos simples, sistematizada em quadros, o que possibilita uma leitura horizontal (observam-se as diferenças) e vertical (observam-se as semelhanças).

\section{Tópico 1 - Presente do Indicativo}

Quadro 1 - Indicativo Presente dos Verbos do Grupo A

\begin{tabular}{|r|c|r|r|r|r|r||}
\hline Verbo & eu & ele/você & eles/vocês & tu & \multicolumn{1}{c|}{ nós } & \multicolumn{1}{c|}{ vós } \\
\hline dizer & Digo & diz & dizem & dizes & dizemos & dizeis \\
\hline fazer & Faço & faz & fazem & fazes & Fazemos & fazeis \\
\hline trazer & trago & traz & trazem & trazes & Trazemos & trazeis \\
\hline
\end{tabular}


Com base nessa distribuição, chega-se às conclusões: (a) no presente do indicativo, as formas se distribuem em dois subgrupos: o da tônica na vogal do radical (formas rizotônicas) nas pessoas gramaticais eu, ele/você, eles/vocês, tu; e o da tônica fora da vogal do radical (formas arrizotônicas) nas formas correspondentes aos pronomes nós e vós; (b) a forma da primeira pessoa do singular termina numa vogal átona grafada com a letra o, sua marca distintiva ; e (3) a forma da terceira pessoa do singular deriva as outras quatro, com o acréscimo das respectivas marcas distintivas, servindo de base para o esquema das desinências pessoais, também usado em outros tempos verbais:

$$
\begin{aligned}
\text { eles/vocês } & \Rightarrow 3^{\mathrm{a}} \text { pessoa do singular }+ \text { nasal (grafia } \mathrm{m} \text {, silaba átona) } \\
\text { tu } & \Rightarrow 3^{\mathrm{a}} \text { pessoa do singular }+\mathbf{s} \\
\text { nós } & \Rightarrow 3^{\mathrm{a}} \text { pessoa do singular }+ \text { mos } \\
\text { vós } & \Rightarrow 3^{\mathrm{a}} \text { pessoa do singular }+ \text { is }
\end{aligned}
$$

Esses conhecimentos adquiridos serão reutilizados em todas as situações em que ocorrerem, servindo como recurso de fixação e como ponto de partida para a aquisição do conhecimento novo.

Quadro 2 - Indicativo Presente dos verbos do Grupo B

\begin{tabular}{||c|r|c|r|r|r|r||}
\hline Verbo & eu & ele/você & eles/vocês & \multicolumn{1}{c|}{ tu } & \multicolumn{1}{c|}{ nós } & \multicolumn{1}{c|}{ vós } \\
\hline dar & dou & dá & dão & dás & damos & dais \\
\hline estar & estou & está & estão & estás & estamos & estais \\
\hline ser & sou & é & são & és & somos & sois \\
\hline
\end{tabular}

As conclusões a que se chega pela leitura desse quadro decorrem da integração interdisciplinar com o tópico regras de acentuação. Assim: (a) a primeira pessoa do singular tem a sua marca distintiva expressa por uma vogal tônica, grafada com as duas vogais ou, ${ }^{6}$ opondo-se à grafia o; (b) as

A representação gráfica do fonema /o/ com duas vogais ou também ocorre em palavras que não pertencem à categoria dos verbos, tanto em sílabas tônicas (ouro, tesouro, couro, mouro, Moura. Douro), quanto em sílabas átonas pretônicas (dourado, pousado, mourisco). Essa combinação de duas vogais, erroneamente classificadas como ditongo, 
formas da $3^{a}$ e da $2^{a}$ pessoa do singular são acentuadas, como monossílabas tônicas terminadas em a(s) e e(s) e oxitonas terminadas em a(s) ; (c) as formas de $2^{\mathrm{a}}$ pessoa, homófonas, se distinguem graficamente pela aplicação do esquema das desinências pessoais; e (d) as flexões sou/é, servem de critério para a organização das outras em dois subgrupos: o que mantém o s do radical (sou, são, somos, sois) e o que não o mantém (é, és).

Quadro 3 - Indicativo Presente dos verbos do Grupo C

\begin{tabular}{||l|r|r|r|r|r|r||}
\hline Verbo & \multicolumn{1}{|c|}{ eu } & ele/você & eles/vocês & tu & nós & \multicolumn{1}{c|}{ vós } \\
\hline pôr & ponho & põe & põem & pões & pomos & pondes \\
\hline ter & tenho & tem & têm & tens & temos & tendes \\
\hline vir & venho & vem & vêm & vens & vimos & vindes \\
\hline
\end{tabular}

Além da identificação de conhecimentos anteriores, observa-se nas formas do quadro 3: (a) a presença do dígrafo nh apenas na primeira pessoa do singular desses três verbos, ${ }^{7}$ precedendo a sua marca distintiva; (b) a manutenção, na primeira pessoa do plural, da vogal do infinitivo: ter $\Rightarrow$ temos vir $\Rightarrow$ vimos - pôr $\Rightarrow$ pomos; $^{8}$ (c), uma adaptação ortográfica, na segunda pessoa do singular, do $\mathbf{m}$ para o $\mathbf{n}$, diante da letra s; ${ }^{9}$ (d) a impossibilidade de seguir-se o esquema das desinências pessoais o que aconteceu na forma de $3^{a}$ pessoa do plural dos verbos ter e vir, pois a forma do singular (tem/vem) já é nasal, fato indicado pela letra $\mathbf{m}$; a distinção,

pela influência visual da escrita, se situa na categoria dos digrafos, uma vez que um único fonema é representado por duas letras.

7 Essa observação se torna pertinente, pois há um "erro previsivel", explicado pela analogia com a grafia da primeira pessoa, nas outras formas nasais: "ponhe", "tenhe" "venhe" são formas muito freqüentes nos textos dos alunos.

8 O uso desse artifício didático tem por objetivo evitar outro "erro previsivel": o uso, na língua oral corrente, da forma "viemos", do pretérito perfeito do indicativo, como se fosse do presente do indicativo.

9 Essa passagem $\mathrm{m} \Rightarrow \mathrm{ns}$ ocorre em outras situações não verbais, como é o caso da formação do plural das palavras terminadas em $\mathbf{m}$ ( nuvem $\Rightarrow$ nuvens). Não se escreve $\mathbf{s}$ depois de $\mathbf{m}$ no sistema ortográfico da língua portuguesa. 
então, foi feita com outro recurso gráfico: o acento circunflexo diferencial, nas formas do plural, têm e vêm; e (e) o desrespeito ao esquema das desinências pessoais na forma correspondente ao pronome vós; nesse caso, exige-se um esforço de memória para guardar o que foge à regra, mas com a ajuda de um artifício didático, graças à existência de um traço comum nessas três formas: a vogal da primeira silaba é nasal (pon/ten/vin) seguida da silaba átona des. ${ }^{10}$

Quadro 4 - Indicativo presente dos verbos do Grupo D

\begin{tabular}{|c|r|r|r|r|r|r||}
\hline Verbo & \multicolumn{1}{|c|}{ eu } & ele/você & eles/vocês & \multicolumn{1}{c|}{ tu } & nós & \multicolumn{1}{c|}{ vós } \\
\hline crer & creio & crê & crêem & crês & cremos & credes \\
\hline ler & leio & lê & lêem & lês & lemos & ledes \\
\hline ver & vejo & vê & vêem & vês & vemos & vedes \\
\hline rir & rio & ri & riem & ris & rimos & rides \\
\hline ir & vou & vai & vão & vais & vamos & ides \\
\hline
\end{tabular}

A observação desse quadro permite a identificação de fatos já conhecidos relacionados ao tópico estudado e a conteúdos intradisciplinares. Uma nova integração, no entanto, pode ser feita, com as regras de acentuação, nas formas crêem, lêem, vêem; também se identifica a ocorrência de ditongação da vogal tônica na primeira pessoa do singular dos verbos crer e ler. ${ }^{11}$ Além disso, como, na $2^{a}$ pessoa do plural, não se respeita o esquema das desinências pessoais, apelase para o esforço da memória, apoiado num artifício didático que leva à identificação de uma regularidade: a primeira sílaba dessas formas é a mesma do infinitivo, e a segunda, des. Assim:

crer $\Rightarrow$ credes - ler $\Rightarrow$ ledes - ver $\Rightarrow$ vedes - ir $\Rightarrow \mathbf{i d e s ~ - ~} \mathrm{rir} \Rightarrow$ rides.

10 Mais uma vez se comprova a importância da apresentação dos verbos em grupos e do estudo de um mesmo tempo verbal. Só assim percebem-se essas semelhanças.

"Nas formas creio e leio, há uma alteração morfofonêmica, com ditongação da vogal tônica ( $\mathrm{e} \Rightarrow \mathrm{ei}$ ), que se mantém em todas as formas do presente do subjuntivo. 
Quadro 5 - Indicativo presente dos verbos do Grupo E

\begin{tabular}{|l|c|c|c|c|c|c|}
\hline Verbo & eu & ele/você & eles/vocês & tu & nós & vós \\
\hline caber & caibo & cabe & cabem & cabes & cabemos & cabeis \\
\hline saber & sei & sabe & sabem & sabes & sabemos & sabeis \\
\hline
\end{tabular}

Nesses verbos, aplica-se o esquema das desinências pessoais, só havendo necessidade de serem destacadas as alterações morfofonêmicas presentes na $1^{\text {a }}$ pessoa do singular. $^{12}$

\section{Tópico 2 - Subjuntivo presente}

Para a conjugação do subjuntivo presente, convém utilizar-se outra forma de agrupamento para os verbos, tomando-se como critério a terminação da $1^{\text {a }}$ pessoa do singular de presente do indicativo: o grupo $F$, em o (final átona); e o grupo $\mathrm{G}$, em ou (final tônica).

$\begin{array}{lllll}\text { Grupo } \mathrm{F}: & \text { digo } \Rightarrow \text { diga } & \text { faço } \Rightarrow \text { faça } & \text { trago } \Rightarrow \text { traga } & \text { ponho } \Rightarrow \text { ponha } \\ & \text { rio } \Rightarrow \text { ria } & \text { creio } \Rightarrow \text { creia } & \text { leio } \Rightarrow \text { leia } & \text { tenho } \Rightarrow \text { tenha } \\ & \text { vejo } \Rightarrow \text { veja } & \text { caibo } \Rightarrow \text { caiba } & \text { sei } \Rightarrow \text { saiba } & \text { venho } \Rightarrow \text { venha }\end{array}$

Grupo G: $\quad$ sou $\Rightarrow$ seja $\quad$ estou $\Rightarrow$ esteja $\quad$ vou $\Rightarrow$ vá $\quad$ dou $\Rightarrow$ dê

Isso porque, os que pertencem ao grupo $F$ têm 0 subjetivo presente formado diretamente da $1^{\text {a }}$ pessoa do singular, substituindo-se a marca do presente do indicativo (vogal o átona) pela marca do presente do subjuntivo (vogais

12 Essa alteração morfofonêmica não requer esforço de memorização (talvez de correção de pronúncia em alunos em cujo registro se observa uma simplificação do sistema verbal, mantendo-se a marca da $1^{\text {" pessoa do }}$ singular do presente do indicativo, a vogal o, pelo uso da forma "seio", homônima do substantivo), pois, aplicado o artifício didático do emprego da palavra-teste, o falante nativo emprega a forma verbal corretamente. Essa dupla existência de formas - a irregular, da norma culta, e a "regular", típica de um registro de natureza social --, permitiu, como recurso estilístico, o jogo de palavras inteligentemente improvisado por Emilio de Meneses, quando the perguntaram se sabia o que a mulher tem de mais belo. Respondeu rápido: "sei-o" (Nesse caso, a ambigüidade se revela apenas no nível fônico). 
átonas e - nos verbos da $1^{\text {a }}$ conjugação - ou a - nos verbos da $2^{a}$ e da $3^{a}$ conjugação); e os que pertencem ao grupo $G$ vão ter a marca do indicativo presente substituída pela seqüência eja, pela vogal a (tônica) ou pela vogal e (oral fechada).

O Subjuntivo presente tem cinco formas diferentes: a $1^{\mathrm{a}}$ e a $3^{a}$ pessoa do singular são iguais. As outras pessoas vão seguir o esquema das desinências pessoais.

Quadro 6 - Subjuntivo presente dos verbos selecionados

\begin{tabular}{|r|rr|r|r|r||}
\hline Verbos & eu - ele/você & eles/vocês & \multicolumn{1}{c|}{ tu } & \multicolumn{1}{c|}{ nós } & \multicolumn{1}{c|}{ vós } \\
\hline dizer & diga & digam & digas & digamos & digais \\
\hline fazer & faça & façam & faças & façamos & façais \\
\hline trazer & traga & tragam & tragas & tragamos & tragais \\
\hline pôr & ponha & ponham & ponhas & ponhamos & ponhais \\
\hline ter & tenha & tenham & tenhas & tenhamos & tenhais \\
\hline vir & venha & venham & venhas & venhamos & venhais \\
\hline ler & creia & creiam & creias & creiamos & creiais \\
\hline rir & leia & leiam & leias & leiamos & leiais \\
\hline caber & caiba & caibam & caibas & caibamos & caibais \\
\hline saber & saiba & saibam & saibas & saibamos & saibais \\
\hline ser & seja & sejam & sejas & sejamos & sejais \\
\hline ver & veja & vejam & vejas & vejamos & vejais \\
\hline estar & esteja & estejam & estejas & estejamos & estejais \\
\hline dar & dê & dêem & dês & demos & deis \\
\hline ir & vá & vão & vás & vamos & vades \\
\hline \hline
\end{tabular}

Como acontece no indicativo presente, a sílaba tônica não se mantém estável. Há o subgrupo das formas rizotônicas (as pessoas do singular e a $3^{a}$ pessoa do plural) e o das formas arrizotônicas ( $1^{a}$ e $2^{a}$ pessoa do plural), que se distinguem apenas pelas terminações que Ihes são próprias. ${ }^{13}$ A única flexão a ser memorizada, por não se enquadrar na regra é vades. Reencontra-se uma homofonia nas formas dês/deis, resolvida graficamente pela aplicação do esquema das desinências pessoais.

13 Essa informação tem sua importância, porque existem formas que soam muito estranhas para os alunos, como digais/façais/tragais/ ponhais/tenhais/venhais. 


\section{Tópico 3 - O Imperativo}

O Imperativo ${ }^{14}$ tem formas correspondentes a cinco pessoas gramaticais: não há o $e u^{15}$, nem o ele/ela/eles/elas (não se exerce a função conativa da linguagem para a pessoa de quem se fala, ausente da situação de comunicação). Essas formas seguem a seqüência $C$, com dois subgrupos: o das pessoas gramaticais mais freqüentemente usadas (você, vocês e nós); o das menos empregadas (tu e vós).

Quadro 7 - Imperativo negativo dos verbos selecionados

\begin{tabular}{|c|c|c|c|c|c|}
\hline Verbos & você & vocês & nós & tu & vós \\
\hline dizer & não diga & não digam & nãก digam & não digas & não digais \\
\hline zer & f faça & & $\mathbf{s}$ & as & cais \\
\hline azer & o traga & não tragam & $\mathbf{s}$ & as & 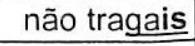 \\
\hline lar & não dê & ão dêem & & não dês & 0 deis \\
\hline estar & não esteja & não estejam & não este & não estejas & não estejais \\
\hline ser & eja & $\mathrm{m}$ & s & não sejas & não sejais \\
\hline pôr & não ponha & onham & não & não ponhas & não ponhais \\
\hline ter & não tenha & não tenham & não tenl & nhas & não tenhais \\
\hline ver & a & 4 & s & não vejas & não vejais \\
\hline crer & não creia & não creiam & não c & não creias & eiais \\
\hline ler & não leia & não leiam & não leiamos & não leias & eiai \\
\hline ir & não vá & não vão & não vamos & não vás & nãc \\
\hline rir & não ria & não riam & não riamos & não rias & não riais \\
\hline vir & não venha & não venham & não venhamos & não venhas & não venhais \\
\hline saber & não saiba & não saibam & não saibamos & não saibas & não saibai \\
\hline
\end{tabular}

O imperativo negativo recebe todas as suas formas do presente do subjuntivo, retirando-se os pronomes pessoais (que não são ditos ou, quando o são, pospõem-se às formas do imperativo), e precedendo-as do advérbio não. Com base nos subjuntivos do tópico anterior, formam-se os imperativos ${ }^{16}$ negativos.

14 Cf. LIMA, Renira Lisboa de Moura. O ensino da redação: formas de expressão imperativa. Curitiba: HD Livros, 1995.

is A não ser estilisticamente e, nesse caso, muda-se o ato de fala.

16 O verbo caber, por sua natureza semântica, não admite imperativo. 
Já o imperativo afirmativo vai ser alimentado por duas fontes: o primeiro subgrupo de pessoas gramaticais (você/vocês/nós) provém do subjuntivo presente, sendo iguais as formas negativa e afirmativa; e o segundo subgrupo (tu/vós), do indicativo presente e, por isso, as formas afirmativas são diferentes das negativas.

Quadro 8 - Imperativo afirmativo dos verbos selecionados

\begin{tabular}{|c|c|c|c|c|c|}
\hline Verbos & você & vocês & nós & tu & vós \\
\hline dizer & diga & digam & digamos & $\underline{\text { dize }}$ & dizei \\
\hline fazer & faça & façam & façamos & faze & fazei \\
\hline trazer & traga & tragam & tragamos & traze & trazei \\
\hline dar & dê & dêem & demos & dá & dai \\
\hline estar & esteja & estejam & estejamos & está & estai \\
\hline ser & seja & sejam & sejamos & sê & sede \\
\hline pôr & ponha & ponham & ponhamos & põe & ponde \\
\hline ter & tenha & tenham & tenhamos & tem & tende \\
\hline ver & veja & vejam & vejamos & vê & vede \\
\hline crer & creia & creiam & creiamos & crê & crede \\
\hline ler & leia & leiam & leiamos & lê & lede \\
\hline ir & vá & vão & vamos & vá & ide \\
\hline rir & ria & riam & riamos & ri & ride \\
\hline vir & venha & venham & venhamos & vem & vinde \\
\hline saber & saiba & saibam & saibamos & sabe & sabei \\
\hline
\end{tabular}

Como essas formas foram retiradas de tempos verbais anteriormente estudados, revêem-se conhecimentos anteriores: esquema das desinências pessoais, regras de acentuação, homofonia e heterografia das formas ( $2^{a}$ pessoa do singular e do plural).

\section{Tópico 4 - Pretérito Imperfeito do Indicativo}

O pretérito imperfeito deriva do presente do indicativo: à $3^{a}$ pessoa do singular acrescenta-se a marca do pretérito imperfeito (va, para os verbos da $1^{\text {a }}$ conjugação e ia, para os verbos das outras conjugações):

$$
\text { está } \Rightarrow \text { estava; dá } \Rightarrow \text { dava; diz } \Rightarrow \text { dizia; faz } \Rightarrow \text { fazia; traz } \Rightarrow \text { trazia }
$$


Nos verbos em que essa pessoa termina com a vogal e, átona ou tônica acentuada, ou i essa vogal cai antes de colocar-se esse sufixo modotemporal. Assim:

lê $\Rightarrow$ lia; $\quad$ cabe $\Rightarrow$ cabia; vê $\Rightarrow$ via;

sabe $\Rightarrow$ sabia; $\quad$ crê $\Rightarrow$ cria; $\quad$ ri $\Rightarrow$ ria

Alguns verbos irregulares não seguem essa regra, como, por exemplo, os verbos ser (é $\Rightarrow$ era) e ir (vai $\Rightarrow$ ia). Mas isso não pode ser visto como um problema, nem vai requerer esforço de memória, porque qualquer falante nativo transporá corretamente para o pretérito imperfeito do indicativo qualquer oração, desde que the seja pedido que a coloque depois das palavras-teste com certeza, antigamente. Esse artifício didático é, pois, de grande utilidade, aplicando-se a todas as situações. Vejam-se os exemplos:

Ela faz tricô . $\quad \Rightarrow$ Com certeza, antigamente, ele fazia tricô.

Ele agora é feliz. $\Rightarrow$ Com certeza, antigamente, ele era feliz.

Ele vai ao teatro. $\Rightarrow$ Com certeza, antigamente, ele ia ao teatro.

Conhecida a primeira pessoa, as outras são construidas de acordo com o esquema de desinências pessoais.

Quadro 9 - Pretérito imperfeito do indicativo dos verbos selecionados

\begin{tabular}{||c|r|r|r|r|r||}
\hline Verbo & eu-ele/você & eles/vocês & \multicolumn{1}{c|}{ tu } & \multicolumn{1}{c|}{ nós } & \multicolumn{1}{c|}{ vós } \\
\hline dizer & dizia & diziam & dizias & diziamos & dizieis \\
\hline fazer & fazia & faziam & fazias & faziamos & faziéis \\
\hline trazer & trazia & traziam & trazias & traziamos & trazieis \\
\hline dar & dava & davam & davas & dávamos & dáveis \\
\hline estar & estava & estavam & estavas & estávamos & estáveis \\
\hline ser & era & eram & eras & éramos & éreis \\
\hline pôr & punha & punham & punhas & púnhamos & púnheis \\
\hline ter & tinha & tinham & tinhas & tinhamos & tínheis \\
\hline ver & via & viam & vias & viamos & víeis \\
\hline crer & cria & criam & crias & criamos & crieieis \\
\hline ler & lia & liam & lias & liamos & lieis \\
\hline ir & ia & iam & ias & iamos & íeis \\
\hline rir & ria & riam & rias & riamos & ríeis \\
\hline vir & vinha & vinham & vinhas & vinhamos & vinheis \\
\hline caber & cabia & cabiam & cabias & cabiamos & cabieis \\
\hline saber & sabia & sabiam & sabias & sabiamos & sabieieis \\
\hline
\end{tabular}


Comparando-se as formas acima, observa-se: (a) a silaba tônica recai sempre na mesma sílaba; (b) as formas correspondentes às $1^{\mathrm{a}}$ e $2^{\mathrm{a}}$ pessoa do plural apresentam um traço comum: são sempre acentuadas por serem, respectivamente, palavras proparoxitonas ou paroxitonas terminadas em ditongo; (c) ocorrência de uma mudança morfofonêmica - a vogal átona a, da $2^{\mathrm{a}}$ pessoa do plural, altera-se, grafando-se com a letra e (destaque, no quadro, com negrito e sublinhado).

\section{Tópico 5 - Pretérito Perfeito do Indicativo}

O pretérito perfeito do indicativo não segue o esquema das desinências pessoais, aplicado nos outros tempos verbais do indicativo e do subjuntivo. Por isso, as pessoas gramaticais vão ser dispostas segundo a seqüência B (eu - ele/você; eles/vocês; nós - tu - vós). A primeira e a terceira pessoa do singular, apesar de sua irregularidade, são sempre tidas como conhecidas de qualquer falante (uma delas, sublinhada na apresentação, oferece a sillaba inicial que vai ser mantida nas outras formas), e são utilizadas adequadamente, aplicando-se as palavras-teste com certeza, ontem:

Eu vou ao cinema $\Rightarrow$ Com certeza, ontem eu fui ao cinema.

É a terceira ou, às vezes, a primeira pessoa do singular (destacadas no quadro) que forma as outras, com o acréscimo das marcas ram ( $3^{a}$ pessoa do plural), mos ( $1^{a}$ pessoa do plural), ste ( $2^{\mathrm{a}}$ pessoa do singular) e stes ( $2^{\mathrm{a}}$ pessoa do plural). Nesse tempo verbal, é o $\mathbf{S}$ que estabelece a oposição entre 0 singular e o plural da segunda pessoa.

Nessa distribuição (Quadro 10, a seguir) verifica-se que a silaba tônica recai na mesma posição em todas as formas e que há uma homonímia entre as formas dos verbos ir e ser, sendo a situação de uso que desfaz - facilmente - a ambigüidade. 
Quadro 10 - Pretérito perfeito do indicativo dos verbos selecionados

\begin{tabular}{||c|c|c|r|r|r|r||}
\hline verbo & eu & ele/você & eles/vocês & \multicolumn{1}{c|}{ nós } & \multicolumn{1}{c|}{ tu } & \multicolumn{1}{c|}{ vós } \\
\hline dizer & $\underline{\text { disse }}$ & $\underline{\underline{\text { disse}}}$ & disseram & dissemos & disseste & dissestes \\
\hline fazer & $\underline{\text { fiz }}$ & fez & fizeram & fizemos & fizeste & fizestes \\
\hline trazer & $\underline{\underline{\text { trouxe}}}$ & $\underline{\underline{\text { trouxe}}}$ & trouxeram & trouxemos & trouxeste & trouxestes \\
\hline dar & $\underline{\underline{\text { dei }}}$ & $\underline{\underline{\text { deu}}}$ & deram & demos & deste & destes \\
\hline estar & estive & esteve & estiveram & estivemos & estiveste & estivestes \\
\hline ser & fui & $\underline{\text { foi }}$ & foram & fomos & foste & fostes \\
\hline ir & fui & $\underline{\text { foi }}$ & foram & fomos & foste & fostes \\
\hline ter & $\underline{\text { tive }}$ & teve & tiveram & tivemos & tiveste & tivestes \\
\hline ver & $\underline{\text { vi }}$ & $\underline{\text { viu }}$ & viram & vimos & viste & vistes \\
\hline crer & cri & $\underline{\text { creu }}$ & creram & cremos & creste & crestes \\
\hline ler & li & leu & leram & lemos & leste & lestes \\
\hline pôr & pus & pôs & puseram & pusemos & puseste & pusestes \\
\hline rir & ri & $\underline{\text { riu }}$ & riram & rimos & riste & ristes \\
\hline vir & $\underline{\text { vim }}$ & veio & vieram & viemos & vieste & viestes \\
\hline caber & $\underline{\text { coube }}$ & $\underline{\text { coube }}$ & couberam & coubemos & coubeste & coubestes \\
\hline saber & $\underline{\text { soube }}$ & $\underline{\text { soube }}$ & souberam & soubemos & soubeste & soubestes \\
\hline
\end{tabular}

O conhecimento do pretérito perfeito do indicativo é de grande utilidade, pois vai servir de base para a formação de três tempos verbais: um, do indicativo, o mais-que-perfeito; e dois, do subjuntivo: o pretérito imperfeito e o futuro.

\section{Tópico 6 - Pretérito mais-que-perfeito do indicativo}

Em sua forma simples, ${ }^{17}$ esse tempo verbal é identificado pela aplicação das palavras-teste com certeza, antes disso:

Com certeza ontem ele fez o trabalho./Com certeza, antes disso, ele já fizera o seu trabalho.

Apresenta cinco formas (a primeira e a terceira pessoa do singular são iguais), provindas da $3^{a}$ pessoa do plural do pretérito perfeito do indicativo sem a sua marca distintiva

${ }^{17}$ A forma simples do pretérito mais-que-perfeito do indicativo soa estranha na língua oral corrente. É a sua forma composta que é utilizada: Com certeza, antes disso, ele já tinha feito o seu trabalho. 
(nasal, indicada pela letra $\mathrm{m}$ ) a que se aplica o esquema de desinências pessoais. ${ }^{18}$ Assim:

$\begin{aligned} \text { foram } & \Rightarrow \text { fora } & \text { deram } & \Rightarrow \text { dera } & \text { estiveram } & \Rightarrow \text { estivera } \\ \text { couberam } & \Rightarrow \text { coubera } & \text { souberam } & \Rightarrow \text { soubera } & \text { viram } & \Rightarrow \text { vira } \\ \text { leram } & \Rightarrow \text { lera } & \text { creram } & \Rightarrow \text { crera } & \text { riram } & \Rightarrow \text { rira } \\ \text { disseram } & \Rightarrow \text { dissera } & \text { fizeram } & \Rightarrow \text { fizera } & \text { trouxeram } & \Rightarrow \text { trouxera } \\ \text { puseram } & \Rightarrow \text { pusera } & \text { vieram } & \Rightarrow \text { viera } & \text { tiveram } & \Rightarrow \text { tivera }\end{aligned}$

Quadro 11 - Pretérito mais-que-perfeito do indicativo dos verbos selecionados

\begin{tabular}{|r|r|r|r|r|r||}
\hline Verbo & eu-ele/você & eles/vocês & \multicolumn{1}{c|}{ tu } & \multicolumn{1}{c|}{ nós } & \multicolumn{1}{c|}{ vós } \\
\hline dizer & dissera & disseram & disseras & disséramos & disséreis \\
\hline fazer & fizera & fizeram & fizeras & fizéramos & fizéreis \\
\hline trazer & trouxera & trouxeram & trouxeras & trouxéramos & trouxéreis \\
\hline dar & dera & deram & deras & déramos & déreis \\
\hline estar & estivera & estiveram & estiveras & estivéramos & estivéreis \\
\hline ser & fora & foram & foras & fôramos & fôreis \\
\hline ir & fora & foram & foras & fôramos & fôreis \\
\hline ter & tivera & tiveram & tiveras & tivéramos & tivéreis \\
\hline ver & vira & viram & viras & viramos & vireis \\
\hline crer & crera & creram & creras & crêramos & crêreis \\
\hline ler & lera & leram & leras & lêramos & lêreis \\
\hline pôr & pusera & puseram & puseras & puséramos & puséreis \\
\hline rir & rira & riram & riras & ríramos & ríreis \\
\hline vir & viera & vieram & vieras & viéramos & viéreis \\
\hline caber & coubera & couberam & couberas & coubéramos & coubéreis \\
\hline saber & soubera & souberam & souberas & soubéramos & soubéreis \\
\hline
\end{tabular}

Verifica-se na distribuição apresentada: (a) uma alteração morfofonêmica, na $2^{\mathrm{a}}$ pessoa do plural, motivada pelo ambiente fonético; (b) a aplicação das regras de acentuação, no plural ( $1^{\mathrm{a}}$ e $2^{\mathrm{a}}$ pessoas).

18 Convém ressaltar a existência de uma homofonia e uma homografia na $3^{\text {a }}$ pessoa do plural dos pretéritos perfeito e mais-que-perfeito do indicativo. A ambigüidade se desfaz com o artifício da variação das pessoas gramaticais. 


\section{Tópico 7 - Pretérito imperfeito do subjuntivo}

Identificado com o uso das palavras-teste Talvez antigamente (Antigamente ele sabia/Talvez antigamente ele soubesse), o pretérito imperfeito do subjuntivo é derivado do pretérito perfeito do indicativo: da $3^{\text {a }}$ pessoa do plural desse tempo primitivo retiram-se o sufixo modotemporal $e$ as desinências numeropessoais, obtendo-se, assim, a $1^{\text {a }}$ e a $3^{\mathrm{a}}$ pessoas do singular do tempo derivado. A essa forma se aplica o esquema das desinências pessoais para a formação das outras pessoas gramaticais. Obtêm-se, então:

$\begin{array}{lllll}\text { foram } & \Rightarrow \text { fosse } & \text { deram } & \Rightarrow \text { desse } & \text { estiveram } \Rightarrow \text { estivesse } \\ \text { couberam } & \Rightarrow \text { coubesse } & \text { souberam } \Rightarrow \text { soubesse } & \text { viram } \Rightarrow \text { visse } \\ \text { leram } & \Rightarrow \text { lesse } & \text { riram } & \Rightarrow \text { risse } & \text { creram } \Rightarrow \text { cresse } \\ \text { disseram } & \Rightarrow \text { dissesse } & \text { fizeram } \Rightarrow \text { fizesse } & \text { trouxeram } \Rightarrow \text { trouxesse } \\ \text { puseram } & \Rightarrow \text { pusesse } & \text { vieram } \Rightarrow \text { viesse } & \text { tiveram } \Rightarrow \text { tivesse }\end{array}$

Quadro 12 - Pretérito imperfeito do indicativo dos verbos selecionados

\begin{tabular}{|c|r|r|r|r|r|}
\hline Verbos & eu-ele/você & eles/vocês & \multicolumn{1}{c|}{ tu } & \multicolumn{1}{c|}{ nós } & \multicolumn{1}{c|}{ vós } \\
\hline dizer & dissesse & dissessem & dissesses & disséssemos & dissésseis \\
\hline fazer & fizesse & fizessem & fizesses & fizéssemos & fizésseis \\
\hline trazer & trouxesse & trouxessem & trouxesses & trouxéssemos & trouxésseis \\
\hline dar & desse & dessem & desses & déssemos & désseis \\
\hline estar & estivesse & estivessem & estivesses & estivéssemos & estivésseis \\
\hline ser & fosse & fossem & fosses & fôssemos & fôsseis \\
\hline ir & fosse & fossem & fosses & fôssemos & fôsseis \\
\hline ter & tivesse & tivessem & tivesses & tivéssemos & tivésseis \\
\hline ver & visse & vissem & visses & vissemos & visseis \\
\hline crer & cresse & cressem & cresses & crêssemos & crêsseis \\
\hline ler & lesse & lessem & lesses & lêssemos & lêsseis \\
\hline pôr & pusesse & pusessem & pusesses & puséssemos & pusésseis \\
\hline rir & risse & rissem & risses & ríssemos & risseis \\
\hline vir & viesse & viessem & viesses & viéssemos & viésseis \\
\hline caber & coubesse & coubessem & coubesses & coubéssemos & coubésseis \\
\hline saber & soubesse & soubessem & soubesses & soubéssemos & soubésseis \\
\hline
\end{tabular}

A observação desse quadro permite a constatação da permanência da sílaba tônica na mesma posição em todas as pessoas e da aplicação de regras de acentuação gráfica ( $1^{a}$ 
pessoa e $2^{a}$ pessoa do plural). É conveniente também chamar a atenção para a grafia do fonema /s/, com o dígrafo SS. ${ }^{19}$

\section{Tópico 8 - Futuro do subjuntivo}

Podendo ser identificado com o a palavra-teste Quando/Se amanhã, esse tempo é sempre usado numa oração subordinada temporal, cuja principal apresenta-se com o verbo no futuro do presente do indicativo (integração intradisciplinar: correspondência de tempos). trabalho. ${ }^{20}$

Se amanhã eu estiver disposta, terminarei este

Também é derivado do pretérito perfeito do indicativo, da $3^{a}$ pessoa do plural: retira-se a terminação am, mantendose o R, marca desse tempo verbal. Assim, obtém-se uma forma idêntica para a $1^{\mathrm{a}}$ e $3^{\mathrm{a}}$ pessoa singular.

$$
\begin{aligned}
\text { couberam } & \Rightarrow \text { couber } & \text { souberam } & \Rightarrow \text { souber } & \text { viram } & \Rightarrow \text { vir } \\
\text { foram } & \Rightarrow \text { for } & \text { deram } & \Rightarrow \text { der } & \text { estiveram } & \Rightarrow \text { estiver } \\
\text { leram } & \Rightarrow \text { ler } & \text { creram } & \Rightarrow \text { crer } & \text { disseram } & \Rightarrow \text { disser } \\
\text { fizeram } & \Rightarrow \text { fizer } & \text { trouxeram } & \Rightarrow \text { trouxer } & \text { puseram } & \Rightarrow \text { puser } \\
\text { vieram } & \Rightarrow \text { vier } & \text { tiveram } & \Rightarrow \text { tiver } & \text { riram } & \Rightarrow \text { rir }
\end{aligned}
$$

A essa forma, aplica-se uma variante do esquema das desinências pessoais, havendo uma diferença na formação da $2^{a}$ pessoa do plural, cuja marca é dada pela seqüência des (conhecimento novo). As formas do futuro do subjuntivo, com manutenção da sílaba tônica na mesma sílaba, estão apresentadas no quadro 13.

Nesse caso, também ocorrem erros previsiveis de grafia: uso da letra $\mathbf{C}$ ("dissece" e até mesmo do pronome SE enclitico, separado por hífen (disse-se).

20 Na lingua oral, o futuro do presente do indicativo é substituido pelo presente do indicativo: Se amanhã eu estiver disposta, termino este trabalho. 
Quadro 13 - Futuro do subjuntivo dos verbos selecionados

\begin{tabular}{|c|c|c|c|c|c|}
\hline Verbo & eu-ele/você & eles/vocês & tu & nós & vós \\
\hline dizer & disser & disserem & disseres & dissermos & disserdes \\
\hline fazer & fizer & fizerem & fizeres & fizermos & fizerdes \\
\hline trazer & trouxer & trouxerem & trouxeres & trouxermos & trouxerdes \\
\hline dar & der & derem & deres & dermos & derdes \\
\hline estar & estiver & estiverem & estiveres & estivermos & estiverdes \\
\hline ser & for & forem & fores & formos & fordes \\
\hline ir & for & forem & fores & formos & fordes \\
\hline ter & tiver & tiverem & tiveres & tivermos & tiverdes \\
\hline ver & vir & virem & vires & virmos & virdes \\
\hline crer & crer & crerem & creres & crermos & crerdes \\
\hline ler & ler & lerem & leres & lermos & lerdes \\
\hline pôr & puser & puserem & puseres & pusermos & puserdes \\
\hline rir & rir & rirem & rires & rirmos & rirdes \\
\hline vir & vier & vierem & vieres & viermos & vierdes \\
\hline caber & couber & couberem & couberes & coubermos & couberdes \\
\hline saber & souber & souberem & souberes & soubermos & souberdes \\
\hline
\end{tabular}

\section{Tópico 9 - Futuro do presente}

Esse tempo verbal é formado do infinitivo ao qual se acrescentam as terminações: ei, á, ás, ão, emos, eis, conforme a fórmula:

Futuro do Presente = Infinitivo + ei, á, ão, ás, emos, ão.

Usado em textos de previsão, é identificado pelas palavras-teste com certeza, amanhã :

Com certeza amanhã choverá no nordeste.

Nessa seqüência (Quadro 14), respeita-se o esquema das desinências pessoais, a partir de uma forma conhecida pelo falante, a terceira pessoa do singular. Outros conhecimentos anteriores são revistos: aplicação de regras de grafia (acentuação e representação escrita do ditongo nasal) e a distinção gráfica (S/ IS) nas formas homófonas da $2^{a}$ pessoa do singular e do plural. 
Quadro 14 - Futuro do presente do indicativo dos verbos selecionados

\begin{tabular}{|c|r|r|r|r|r|r||}
\hline Verbo & ele/você & eles/vocês & \multicolumn{1}{c|}{ tu } & eu & nós & \multicolumn{1}{c||}{ vós } \\
\hline ir & irá & irão & irás & irei & iremos & ireis \\
\hline ser & será & serão & serás & serei & seremos & sereis \\
\hline dar & dará & darão & darás & darei & daremos & dareis \\
\hline estar & estará & estarão & estarás & estarei & estaremos & estareis \\
\hline ter & terá & terão & terás & terei & teremos & tereis \\
\hline caber & caberá & caberão & caberás & caberei & caberemos & cabereis \\
\hline saber & saberá & saberão & saberás & saberei & saberemos & sabereis \\
\hline ver & verá & verão & verás & verei & veremos & vereis \\
\hline vir & virá & virão & virás & virei & viremos & vireis \\
\hline ler & lerá & lerão & lerás & lerei & leremos & lereis \\
\hline crer & crerá & crerão & crerás & crerei & creremos & crereis \\
\hline rir & rirá & rirão & rirás & rirei & riremos & rireis \\
\hline pôr & porá & porão & porás & porei & poremos & poreis \\
\hline \hline
\end{tabular}

Nos três verbos seguintes, embora também se aplique o esquema das desinências pessoais, há um conhecimento novo: o infinitivo (tempo primitivo) perde, por síncope, a sílaba ze, ao formar os seus derivados, obtendo-se as formas: ${ }^{21}$

Quadro 15 - Futuro do presente do indicativo dos verbos fazer, trazer e dizer

\begin{tabular}{||c|r|r|r|r|r|r||}
\hline Verbo & ele/você & eles/vocês & tu & eu & nós & vós \\
\hline fazer & fará & farão & farás & farei & faremos & fareis \\
\hline trazer & trará & trarão & trarás & trarei & traremos & trareis \\
\hline dizer & dirá & dirão & dirás & direi & diremos & direis \\
\hline
\end{tabular}

Verifica-se que, em todas as pessoas, a tônica permanece na mesma posição, no sufixo modotemporal ra/re (tônico). ${ }^{22}$

21 Essas formas são usadas naturalmente pelo nativo, constituindo-se um problema, porém, quando se trata de estrangeiros.

22 Esse sufixo, só aparentemente, é idêntico ao sufixo modotemporal do pretérito mais-que-perfeito do indicativo, pois dele se distingue pela tonicidade: tônico (futuro do presente); átono (pretérito mais-queperfeito). 
A presença das duas variantes do sufixo modotemporal ra/re permite a distribuição das formas do futuro do presente em dois subgrupos: o das formas em e ( $1^{\text {a }}$ pessoa do singular e do plural e a $2^{\mathrm{a}}$ do plural), o das formas em a ( $2^{\mathrm{a}}$ e $3^{\mathrm{a}}$ pessoa do singular e a $3^{\mathrm{a}}$ do plural), justificando-se a seqüência $D$ das pessoas gramaticais proposta para esse tempo verbal. $O$ conhecimento anterior das regras de acentuação também é reutilizado nesse tempo verbal.

\section{Tópico 10 - Futuro do pretérito do indicativo}

Tem a mesma origem do futuro do presente do indicativo, provindo do infinitivo a que se acrescenta a terminação ia, formando-se, dessa forma, a $1^{\mathrm{a}}$ e a $3^{\mathrm{a}}$ pessoa do singular, a que se aplica o esquema das desinências pessoais, segundo a fórmula:

Futuro do pretérito $=$ infinitivo + ia, iam, ias, iamos, ieis

Quadro 16 - Futuro do pretérito do indicativo dos verbos selecionados

\begin{tabular}{||l|r|r|r|r|r||}
\hline Verbos & eu-ele/você & eles/vocês & \multicolumn{1}{c|}{ tu } & \multicolumn{1}{c|}{ nós } & \multicolumn{1}{c|}{ vós } \\
\hline estar & estaria & estariam & estarias & estariamos & estarieis \\
\hline dar & daria & dariam & darias & dariamos & daríeis \\
\hline dizer & diria & diriam & dirias & diriamos & diríeis \\
\hline fazer & faria & fariam & farias & fariamos & faríeis \\
\hline trazer & traria & trariam & trarias & traríamos & traríeis \\
\hline ler & leria & leriam & lerias & leríamos & leríeis \\
\hline ver & veria & veriam & verias & veriamos & veríeis \\
\hline crer & creria & creriam & crerias & creriamos & creríeis \\
\hline caber & caberia & caberiam & caberias & caberíamos & caberieis \\
\hline saber & saberia & saberiam & saberias & saberiamos & saberíeis \\
\hline ir & iria & iriam & irias & iriamos & iríeis \\
\hline ser & seria & seriam & serias & seríamos & seríeis \\
\hline pôr & poria & poriam & porias & poríamos & poríeis \\
\hline rir & riria & ririam & ririas & ririamos & ririeis \\
\hline vir & viria & viriam & virias & viriamos & virieieis \\
\hline ter & teria & ter iam & ter ias & ter íamos & ter íeis \\
\hline
\end{tabular}


Esse quadro permite que, na $2^{\mathrm{a}}$ pessoa do plural, seja identificada a mesma alteração morfofonêmica, na vogal a, átona, verificada em outros tempos verbais e mais uma vez faz-se a integração intradisciplinar, aplicando-se regras de acentuação gráfica, nas $1^{\mathrm{a}}$ e $2^{\mathrm{a}}$ pessoas do plural.

\section{SUGESTÕES COMPLEMENTARES}

A apresentação gradativa de todas as formas; o entrelaçamento do conhecimento adquirido, considerado ponto de partida para a aquisição do conhecimento posterior; a integração intradisciplinar de conhecimentos; o domínio do esquema das desinências pessoais; a aplicação do conhecimento em novas situações; eis as experiências de ensino/aprendizagem, que tornam o aluno capaz de identificar e de conjugar os tempos verbais.

Entretanto, essas experiências ainda não são suficientes. Há uma necessidade de reorganizar o conhecimento adquirido. Isso pode ser feito através de um reagrupamento em novas categorias, atividade que pode ser desenvolvida à medida que semelhanças e diferenças vão sendo percebidas, estabelecendo-se novas relações, reforçando-se a aprendizagem, pela reutilização do conhecimento, mas de maneira diferente. Desse modo, os tempos verbais poderão ser reagrupados, aplicando-se novos critérios: a relação tempos primitivos/tempos derivados; as desinências numeropessoais; o número das formas verbais; as formas acentuadas e não acentuadas da $1^{\mathrm{a}} \mathrm{e}$ da $2^{\mathrm{a}}$ pessoa do plural; as formas com o ditongo nasal /aw/ grafadas com ão e com am; os tempos verbais com as mesmas desinências numeropessoais.

\section{CONCLUSÃO}

Nos exemplos de procedimentos didáticos propostos para o ensino da conjugação verbal em sala de aula, apela-se, sobretudo, para as habilidades de lidar com o conhecimento: observação (percepção de características); comparação 
(identificação de semelhanças e de diferenças); classificação (discriminação intraclasse de que decorrem os agrupamentos com aplicação de critérios); e sistematização (identificação e aplicação de princípios, regras, fórmulas, esquemas).

A aquisição dessas competências não se faz numa aula $^{23}$, nem numa unidade de ensino, nem num ano escolar, mas num continuum, em que os temas básicos, sempre presentes, vão sendo ampliados, aprofundados e integrados, tendo em vista o seu significado na prática da língua, tanto na leitura quanto na produção de textos, para que se possa não apenas identificar e conjugar os tempos verbais, mas também justificar o seu emprego e escolhê-los objetiva e conscientemente, adaptando-os a cada tipo de texto.

O uso dos modos e tempos verbais é também muito complexo e, mesmo assim, esse tópico nem sempre é incluido nos programas de ensino. Muitas vezes, a seleção de um tempo verbal é pré-determinada, devendo ser respeitada por ser uma exigência estrutural. É o que ocorre na estruturação de períodos em que uma correspondência de tempos se estabelece obrigatoriamente entre a oração principal e a oração subordinada. A experiência do emprego dos modos e tempos verbais, entretanto, não se faz numa etapa posterior à aquisição do paradigma da conjugação, mas acompanha cada etapa, sendo vivida à medida que se adquire cada um dos tempos verbais, estudados, assim, do ponto de vista gráfico, morfossintático, semântico e textual, como uma forma de integração intra e interdisciplinar.

Esse assunto não se esgota com este artigo. O que aqui se propôs limita-se aos tempos verbais simples, havendo muito ainda a ser feito com os tempos verbais compostos e com os da voz passiva. O que se defende - o que é mais significativo - é que haja uma variação das experiências pedagógicas, para que se associem os princípios de seleção

A nào ser que seja numa aula expositiva, una atividade culminante. em que os alunos já dominam todo o assunto, podendo o professor apresentalo, numa visão de conjunto, com o auxilio de recursos audiovisuais, ou. entào, em aulas de concurso, em que o candidato precisa e quer demonstrar o seu domínio do conteúdo. 
do conteúdo - continuidade, seqüência e integração - e se favoreça a mobilização das operações cognitivas, apelando-se para a memória apenas nos momentos em que tal decisão se justifica. Defende-se, portanto, que o ensino da lingua materna seja um ensino inteligente, criando-se oportunidades para o uso das habilidades cognitivas, e que os desafios apresentados sejam sustentados por uma concepção de ensino da língua, como o "ensino do cálculo do pensamento", na feliz expressão de Bruner.

\section{REFERÊNCIAS BIBLIOGRÁFICAS}

BRUNER, Jerome S. O ensino da língua. Uma nova teoria da aprendizagem. Trad. de Norah Levy Ribeiro. Rio de Janeiro: Bloch, 1969. p. 121-131.

CUNHA, Celso Ferreira da; CINTRA, Lindley. Nova gramática do português contemporâneo. Rio de Janeiro: Nova Fronteira, 1985.

LIMA, Renira Lisboa de Moura. Ensino da Redação: formas de expressão imperativa. Curitiba: HD Livros, 1995.

REIS, Otelo. Breviário da conjugação de verbos. 38 ed. rev. e atual. Rio de Janeiro: Livraria Francisco Alves, 1978.

TYLER, Ralph. Princípios básicos de currículo e ensino. Trad. Leonel Vallandro. Porto Alegre: Globo, 1974. 